\title{
РИСКИ НЕДОБРОСОВЕСТНОГО ПОВЕДЕНИЯ УЧАСТНИКОВ КОНТРАКТНЫХ ОТНОШЕНИЙ
}

\section{RISKS OF UNFAIR CONDUCT UNDER THE LAW ON THE CONTRACT SYSTEM}

N. Parfenyuk

Summary. Property relations that arise between the state and other entities within the framework of the contract system in the field of procurement do not always have a predictable result and contribute to the achievement of goals, which is due to objective and subjective reasons. One of the objective reasons is the risk of unfair behavior of the parties to the contractual relationship. The current procedure of legal regulation of contractual relations enshrined in the Federal law of April 5, 2013 № 44FL "About contract system in the procurement of goods, works, services for state and municipal needs" contains separate provisions that can reduce the risks of dishonest behavior of parties to contractual relations, but establishes a mechanism of realization of interests of the customer and the participant of the procurement does not yet include well-researched element in the protection of these interests, and adequate legal tools to anticipate risks and minimize their consequences.

Keywords: risk of unfair behavior, contractual relations, risk management, performance of obligations, the principle of good faith.
Парфенюк Наталья Валерьевна Аспирант, Тюменский государственный университет, Тюмень parn_2012@mail.ru

Аннотация. Имущественные отношения, возникающие между государством и другими субъектами в рамках контрактной системы в сфере закупок, не всегда имеют предсказуемый результат и способствуют достижению поставленных целей, что обусловлено причинами объективного и субъективного характера. Одной из объективных причин выступает риск недобросовестного поведения сторон контрактных отношений. Действующий порядок правового регулирования контрактных отношений, закреплённый в нормах Федерального закона от 5 апреля 2013 г. № 44-Ф3 «0 контрактной системе в сфере закупок товаров, работ, услуг для обеспечения государственных и муниципальных нужд", содержит отдельные положения, которые могут снизить риски недобросовестного поведения сторон контрактных отношений, но при этом закрепленный механизм реализации интересов заказчика и участника закупок пока не содержит хорошо проработанного элемента защиты этих интересов и надлежащих правовых средств, позволяющих предвидеть риски и минимизировать их последствия.

Ключевые слова: гражданско-правовой риск, недобросовестное поведение, контрактные отношения, исполнение обязательств, принцип добросовестности.

ных правоотношениях, нельзя не отметить и концепцию рисков в договорных отношениях российского правоведа К.П. Победоносцева, который не только указывал на то, что любой договор сопряжен с риском, но и дифференцировал договорные риски на риски, лежащие в основе договора и риски, не входящие в юридическое содержание договора [19].

Большой вклад в исследование риска в гражданском праве внес доктор юридических наук, профессор В.А. Ойгензихт, определивший, что «риск есть психическое отношение субъектов к результату собственных действий или к поведению других лиц, а также к возможному результату объективного случая и случайно невозможных действий, выражающееся в осознанном допущении отрицательных, в том числе невозместимых, имущественных последствий» [15]. При этом, В.А. Ойгензихт полагал, что риск может являться основанием гражданско-правовой ответственности и при отсутствии вины, но только при наличии признака противоправности в действиях субъекта гражданского правоотношения $[15,16,20]$. Позднее концепцию риска в гражданском праве В.А. Ойгензихта поддержали С.Н. Братусь [5], 
В.А. Копылов [10], А. Г. Мартиросян [12], И.Н. Хмелевский [23] и другие исследователи. Однако, представляется, что понимание риска как условия гражданско-правовой ответственности является исключительно частным проявлением риска.

Категорию риск в обязательственных отношениях не обходят своим вниманием и современные исследователи. Так, М.А. Ковалевский [9], А.Г. Карапетов [8], О.М. Олейник [17] акцентируют внимание на проблеме распределения рисков сторонами договора с позиции теории «преимущественного носителя риска» (superior risk bearer test), разработанной основоположником экономического анализа права, американским правоведом и экономистом Р. Познером. В основу теории Р. Познера положена гипотеза о том, что принятие стороной договора определенного риска должно быть компенсировано за счет стороны, в большей степени информированной о риске [25]. Так, например, при предоставлении помещения в аренду для конкретных целей, например, размещения в нем отеля, убытки и затраты арендатора в случае изъятия помещения из незаконного владения арендодателя должен компенсировать арендодатель. Обусловлено это тем, что потери арендатора для арендодателя были предвидимыми. Таким образом, главным критерием «преимущественного носителя риска» является информированность стороны договора об обстоятельствах, которые другая сторона не могла предвидеть. А.Г. Дудко в своих работах отмечает, что кроме случаев невозможности предотвращения риска определяется та сторона, которая сможет застраховать соответствующий риск с меньшими издержками [7]. При этом, согласно теории Р. Познера, при выборе стороны, за счет которой риск будет компенсироваться, учитывать необходимо не те меры, которые приняты сторонами, а те меры, которые стороны могли бы предпринять.

Анализ исследований о риске в праве показал, что зародившийся в дореволюционном праве интерес к категории «риск», не теряет своей актуальности и сегодня. С.О. Беляев рассматривает риск в контексте механистической модели реальности, «где любая ситуация риска воспринимается всего лишь как ситуация недостаточной информированности, порождаемая неполным знанием всех возможных факторов, влияющих на последствия принятых нами решений» [4]. Такой подход имеет схожесть с теорией преимущественного носителя риска. В рамках данной модели риск - это то, что в принципе всегда может быть сведено к нулю при условии достаточной информированности. В контексте заявленной темы статьи речь может идти о наличии «ассиметричной информации» возникающей при недостаточности знаний одной стороны (государственного заказчика) о своем контрагенте (участнике закупке). И в этой связи риск как гражданско-правовая категория имеет прямую связь с таким универсальным гражданско-правовым механизмом, как принцип добросовестности.

Добросовестность декларируется в качестве необходимой нормы поведения участников различных гражданско-правовых отношений, и несоблюдение такого принципа ведет к рискам недобросовестного поведения сторон. По справедливому замечанию А.Г. Карапетова, несмотря на то, что до 2013 года добросовестность официально в ГК РФ общим началом гражданского права не называлась, то что «совесть» является принципом российского гражданского права, можно было легко вывести из системного толкования законодательства [18].

В контрактных отношениях с участием государства риск недобросовестного поведения сторон контрактных отношений выступает одним из наиболее важных типов рисков, требующих соответствующего контроля и управления. Участники контрактной системы достаточно часто сталкиваются с недобросовестным поведением, например, заказчик с недобросовестным поведением участника закупки, участник закупки с недобросовестным поведением заказчика. Поскольку участники контрактной системы регулярно сталкиваются с недобросовестным поведением, законодатель должен защитить их интересы, переложив все риски недобросовестного поведения на соответствующую сторону гражданского правоотношения. Иными словами, применить субъективную добросовестность, которая представляет собой способ задать некие стандарты поведения и установить те или иные санкции за их нарушение [18]. Действующий порядок правового регулирования контрактных отношений, закреплённый в нормах Федерального закона от 5 апреля 2013 г. № 44-Ф3 «О контрактной системе в сфере закупок товаров, работ, услуг для обеспечения государственных и муниципальных нужд» (далее - Закон о контрактной системе), содержит отдельные положения, которые могут снизить риски недобросовестного поведения сторон контрактных отношений, но при этом закрепленный механизм реализации интересов заказчика и участника закупок пока не содержит хорошо проработанного элемента защиты этих интересов и надлежащих правовых средств, позволяющих предвидеть риски и минимизировать их последствия. И такая ситуация прослеживается во многих нормах Закона о контрактной системе. Это лишает участников данного вида отношений необходимой нормативной опоры, которая могла бы служить основанием для регулирования вопросов об управлении рисками в этой сфере.

В рамках общего содержания принципа добросовестности риск последствий недобросовестного поведения, который влечет за собой юридические последствия в виде взыскания убытков, отказа в защите права и т.д., лежит на недобросовестном лице. Однако, если рассма- 
тривать распределение рисков сторонами договора с позиции теории «преимущественного носителя риска», то компенсация риска распределяется исходя из информированности сторон договора об обстоятельствах, которые другая сторона не могла предвидеть. Получается, что исходя из теории «преимущественного носителя риска» заказчик должен возместить убытки и затраты участника закупки. Практическим примером такой ситуации является незаключение контракта с участником закупки, предложившим лучшую цену по причине обжалования действий заказчика в антимонопольной службе участником закупки, необоснованно не допущенным до участия в аукционе. В качестве затрат здесь можно рассматривать вознаграждение брокера за выдачу банковской гарантии. Заказчик, являясь профессиональным участником контрактной системы (принцип профессионализма заказчика закреплен Законом о контрактной системе), совершая действия по допуску или недопуску участника закупки до участия в аукционе, априори более информирован о тех обстоятельствах, о которых не проинформирован участник закупки. В конкретном примере заказчик может знать, что совершил действия, нарушающие положения законодательства о контрактной системе, но не предпринять никакие меры для того, чтобы это предотвратить. Как уже было отмечено, акцент в теории «преимущественного носителя риска» как раз и делается на том, какие меры стороны могли бы принять.

Систему управления рисками в контрактной системе можно представить как двухуровневую структуру управления рисками. На первом уровне должно происходить управление рисками со стороны государства посредством закрепления нормативных предписаний, а на втором уровне рисками управляют сами участники отношений путем совершения фактических и юридических действий через выбор правовых средств, имеющихся в нормах законодательства. Оба уровня управления могут работать только в своей взаимосвязи - наличие надлежащих правовых средств в Законе о контрактной системе должно позволять осуществлять их выбор для минимизации рисков. Однако, как уже было отмечено, в Законе о контрактной системе закрепленный механизм реализации интересов заказчика и участника закупок не содержит хорошо проработанного элемента защиты интересов субъектов отношений и надлежащих правовых средств, позволяющих предвидеть риски и минимизировать их последствия.

Так, если говорить о рисках, вызванных недобросовестным поведением участников закупок, то для их минимизации государственные заказчики должны осуществлять проверку благонадежности и добросовестности таких лиц на этапе подачи заявок на участие в закупках (ст. 54.7, ст. 69, ст. 78, ст. 82.4., ст. 89 Закона о контрактной системе). В качестве меры по предотвращению рисков государственным заказчикам предоставляется возможность не допускать не соответствующие требованиям документации о закупке извещения об осуществлении закупки и самих участников закупки до участия в ней. Недопущение участников закупки к первичному получению прав (праву быть допущенным к участию в закупке) позволяет снизить риск недобросовестного поведения при исполнении контракта, что служит дополнительной гарантией исполнения обязанностей в отношении государственного заказчика.

Вместе с тем, как уже было отмечено, элемент защиты этих интересов заказчика от рисков недобросовестного поведения недостаточно хорошо проработан. Так, с одной стороны государственный заказчик имеет возможность минимизировать свои риски, не допуская отдельных участников закупок до участия в них, в то время как с другой стороны, объем влияния заказчика на развитие рисковой ситуации минимален. О минимальном объеме влияния говорит тот факт, что заказчик должен полагаться исключительно на ту информацию, которая предоставляется участником закупки на электронной площадке, при этом перепроверять достоверность информации является правом, а не обязанностью заказчика. Но даже свое право на перепроверку предоставленной участником закупки информации в отдельных случаях государственный заказчик реализовать может не всегда ввиду того, что сроки на проверку предоставленной участником закупки информации ограничены императивными нормами Закона о контрактной системе. Все это приводит к тому, что возникает ситуация, при которой заказчик не может минимизировать свои риски.

Сказанное можно проиллюстрировать практическими примерами. Согласно п. 5. ч. 1 ст. 31 Закона о контрактной системе одним из требований, предъявляемых к участникам закупок, является отсутствие у такого участника недоимки по налогам, сборам, задолженности по иным обязательным платежам в бюджеты бюджетной системы Российской Федерации за прошедший календарный год, размер которых превышает двадцать пять процентов балансовой стоимости активов участника закупки по данным бухгалтерской отчетности за последний отчетный период. Положениями п. 3. ч. 1 ст. 31 Закона о контрактной системе установлено и такое требование к участнику закупки, как непроведение ликвидации участника закупки - юридического лица и отсутствие решения арбитражного суда о признании участника закупки - юридического лица или индивидуального предпринимателя несостоятельным (банкротом) и об открытии конкурсного производства. Соответствие участника закупки указанному требованию (исходя из смысла нормативных предписаний Закона о контрактной системе) при проведении электронных конкурентных способов 
определения поставщика (подрядчика, исполнителя) подтверждается участником закупки декларацией о соответствии участника закупки требованиям, установленным пп. 3-9 ч. 1 ст. 31 Закона о контрактной системе. При этом указанная декларация предоставляется с использованием программно-аппаратных средств электронной площадки, смысл которых заключается в подписании электронной подписью соответствующего электронного документа, сформированного не участником закупки, а аппаратными средствами электронной площадки. Риск недобросовестного поведения в данном случае лежит полностью на участнике закупки. Из замысла законодателя следует, что заказчики проверяют поступившую информацию, полностью полагаясь на добросовестность участника закупки: если декларация о соответствии участника закупки подписана электронной подписью, значит участник закупки соответствует предъявляемым к нему требованиям. Но ведь вполне может возникнуть и ситуация, при которой могут обостриться риски недобросовестного поведения со стороны участника закупки. Если предоставлять документы нет необходимости, а у заказчика отсутствует обязанность проверки сведений, указанных в декларации, на их достоверность, то даже при фактическом несоответствии предъявляемым требованиям (например, при наличии задолженностей или нахождения в процедуре банкротства) можно быть допущенным к закупке и даже стать победителем. При этом последствия допусков таких участников, как правило, имеют отрицательные последствия.

Анализ правоприменительной практики позволяет проиллюстрировать вышесказанное примерами. Так, 02.09.2016 МУП «Костромагортранс» стал победителем закупки по лоту № 0841300009016000528 на выполнение работ по осуществлению регулярных перевозок пассажиров и багажа автомобильным транспортом в городском сообщении по регулируемым тарифам по муниципальным маршрутам № 14 «ПМК-2 - Поликлиника-2 (п. Высоково)» и № 44 «п. Высоково - ул. Локомотивная» общей стоимостью 858144 (восемь миллионов пятьсот восемьдесят одна тысяча четыреста сорок четыре) руб. 60 коп., со сроком выполнения работ с 01.10.2016 года по 30.09.2021 года включительно (13.09.2016 года был заключен контракт). 08.09.2016 должник стал победителем закупки по лоту № 0841300009016000527 на выполнение работ по осуществлению регулярных перевозок пассажиров и багажа автомобильным транспортом в городском сообщении по регулируемым тарифам по муниципальным маршрутам № 2 «ВР «Солнечный» - пос. Волжский» и № 9 «ВР «Солнечный» - пл. Сусанинская», общей стоимостью 15803448 (пятнадцать миллионов восемьсот три тысячи четыреста сорок восемь) руб. 18 коп., со сроком выполнения работ с 01.10.2016 года по 30.09.2021 года включительно (19.09.2016 года был заключен контракт № Ф.2016.265008). Указанные контрак- ты заключались в строгом соответствии с положениями Закона о контрактной системе и должны были быть оплачены из средств соответствующих бюджетов бюджетной системы. Однако, участник закупки, с которой были заключены контракты на момент участия в процедуре - МУП «Костромагортранс», не только имел задолженности по налогам, сборам и иным обязательным платежам в бюджеты бюджетной системы Российской Федерации за прошедший календарный год, размер которых превышал двадцать пять процентов балансовой стоимости активов (на момент заключения контрактов размер заложенности МУП «Костромагортранс» перед ФНС г. Костромы составлял около 100 миллионов рублей, в то время как 25\% балансовой стоимости активов на 2016 год составляло около 7,5 миллионов рублей), что подтверждается многочисленными решениями арбитражного суда Костромской области по делу № А3111311/2016 [2]. Впоследствии вышеназванные контракты были расторгнуты, а государству причинён не только имущественный ущерб, но и не были достигнуты цели и решены задачи социально-экономического развития муниципального образования в части осуществления регулярных перевозок пассажиров и багажа.

Как видно из краткого описания практического применения норм Закона о контрактной системе, если бы государственный заказчик хоть как-то мог минимизировать свои риски при проверке участников закупок на соответствие требованиям, установленным законом, за счет хорошо проработанных элементов защиты своих интересов, то подобные ситуации вряд ли имели место быть. Пока же законодательно не заложена надлежащая «степень контроля» за риском недобросовестного поведения участника закупки при подаче информации о соответствии требованиям, установленным Законом о контрактной системе. Кроме того, не регламентирован комплекс мер, направленных на предотвращение рисков недобросовестного поведения участников закупок.

Единственным, на взгляд автора, очевидным элементом защиты от недобросовестного поведения участника закупки выступает установленная законодателем в ч. 15 ст. 95 Закона о контрактной системе обязанность по одностороннему отказу от исполнения контракта со стороны заказчика, если в ходе исполнения контракта установлено, что поставщик (подрядчик, исполнитель) не соответствуют установленным извещением об осуществлении закупки и (или) документацией о закупке требованиям к участникам закупки или представил недостоверную информацию о своем соответствии таким требованиям, что позволило ему стать победителем определения поставщика (подрядчика, исполнителя). Однако выявить недостоверность представляемых сведений не всегда возможно. Указанная ситуация фактически приводит к минимизации рисков для недобро- 
совестных участников закупок при предоставлении информации, что, по сути, стимулирует их к недобросовестному поведению.

Установление в ст. 31 Закона о контрактной системе репутационных ограничений применительно к участникам закупки является формой контроля и управления риском со стороны государства. Основная цель такого контроля и управления - снижение рисков недобросовестного поведения участников закупок, предупреждение нарушения прав заказчиков, осуществляющих закупки. Отсутствие же жестких нормативных требований к порядку проверки предоставляемых участников закупки сведений о своем соответствии ч. 1. ст. 31 Закона о контрактной системе является достоинством и одновременно недостатком. С одной стороны, заказчики имеют возможность минимизировать свои риски, не допуская отдельных участников закупок до участия в таких закупках. С другой стороны, возрастает риск недобросовестного поведения участника закупки, поскольку законодательно заложенная «степень контроля» за риском минимальна.

\section{ЛИТЕРАТУРА}

1. Федеральный закон от 05.04.2013 № 44-Ф3 (ред. от 27.06.2019) «0 контрактной системе в сфере закупок товаров, работ, услуг для обеспечения государственных и муниципальных нужд» (с изм. и доп., вступ. в силу с 01.10.2019) // Собрание законодательства РФ.— 2013.— № 14.— Ст. 1652.

2. Постановление Второго арбитражного апелляционного суда от 17.02 .2020 по делу № А31-11311/2016// СПС «КонсультантПлюс».

3. Агарков М. М. Обязательство по советскому гражданскому праву. - М., 1940.—C. 64.

4. Беляев С. О. Риск как категориальная форма правовой реальности / С. О. Беляев // Философия права.— 2009.— № 2.— C. 17-19.

5. Братусь С. Н. Юридическая ответственность и законность (очерк теории). М.: Городец-издат, 2001. С. 168.

6. Джиоева Е.Г. Гражданско-правовые риски процедур определения поставщика, подрядчика, исполнителя // Российская юстиция.— 2016.— № 1.— C. $9-13$.

7. Дудко А. Г. Существенное изменение обстоятельств как основание изменения или расторжения договора // Вестник Московского университета. Сер. 11. Право. 2000. № 1.

8. Карапетов А. Г. Экономические основания принципа свободы договора // Вестник гражданского права. 2012. № 3. С. 66-154

9. Ковалевский М. А. Правовое значение экономических рисков // Актуальные проблемы науки и практики коммерческого права. Вып. 5. М., 2005;

10. Копылов В.А. 0 категории риска в гражданском праве // Защита субъективных прав: История и современные проблемы. Волгоград: ВолГУ, 2000. С. 53.

11. Магазинер Я. М. Общая теория права на основе советского законодательства // Правоведение.— 1999.— № 1.— С. 136.

12. Мартиросян А. Г. Теория риска в гражданском праве РФ. Монография.— Москва: Проспект, 2016. - 113

13. Мейер Д. И. Русское гражданское право: В 2 ч. 1902. М.: Статут, 1997. Ч. 2. С. 151.

14. Мамчун В.В. 0 понятиях и определениях риска в юридической доктрине и в законодательстве // Вестник Владимирского юридического института.2010. — № 1 (14). - C. 100-109.

15. Ойгензихт В. А. Категория риска в советском гражданском праве // Правоведение. 1971. № 5. С. 67-68.

16. Ойгензихт В.А. К вопросу о понятии риска в гражданском праве // Актуальные проблемы применения советского законодательства. - Душанбе: Изд-во Тадж. ун-та, 1974.-С. 113-126

17. Олейник 0. М. Экономический анализ права в российской науке и практике // Закон. 2014. № 12. С. 52-53.

18. Основные положения гражданского права: постатейный комментарий к статьям 1-16.1 Гражданского кодекса Российской Федерации [Электронное издание. Редакция 1.0]. Отв. ред. А. Г. Карапетов.— Москва: М-Логос, 2020.— 1469 с.

19. Победоносцев К. П. Курс гражданского права. Ч. 3. М.: Статут, 2003 // СПС «КонсультантПлюс».

20. Проблема риска в гражданском праве. Часть общая / Ойгензихт В. А.— Душанбе: Ирфон, 1972.— 224 с.

21. Тасалов Ф. А. Манипулирование недействительностью сделок, заключенных по итогам государственных и корпоративных закупок: антимонопольные и гражданско-правовые риски поставщиков // Вестник арбитражной практики. - 2019. - № 3.— С. 29-37.

22. Тасалов Ф. А. Закупки: от технического задания к исполнению контракта. - М., 2018. - 256 с.

23. Хмелевской И. Н. Проблемы риска в гражданском законодательстве: Дис. ... канд. юрид. наук. М., 2001. С. 57.

24. Шершеневич Г. Ф. Учебник русского гражданского права (по изданию 1907 г.). М.: Фирма «СПАРК», 1995. С. 290.

25. Posner R., Rosenfeld A. Impossibility and Related Doctrines in Contract Law: An Economic Analysis // Economic Analysis of Contract Law, Antitrust Law and Safety Regulations P. 53-88. 